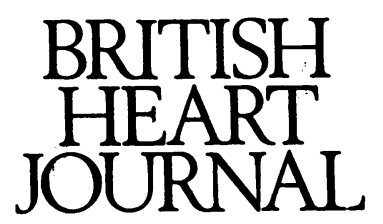

\title{
VIEWPOINT
}

\section{Balloon dilatation of the aortic valve in adults: a surgeon's view}

\author{
Tom Treasure
}

There can be no more fascinating problem in surgery than the relief of pathological conditions of the valves of the heart.

Souttar wrote this to introduce his account of the first mitral commissurotomy, performed in The London Hospital in 1925. He pushed on the door that might have opened the way to valve surgery but it was kept securely shut. ${ }^{1}$ Souttar still has his detractors-and true, there was more mitral regurgitation than would have been ideal both before and after this operation-but rather than listen to the oral tradition which seems to have grown up around this early attempt to open a stenotic valve, read his paper. He knew exactly what he was doing, as regards the surgical approach; the hazards of interfering with cerebral perfusion; and, in particular, what he was doing to the valve. Opinions on the "mechanism" of aortic balloon dilatation show much less insight. ${ }^{2}$ And yet it was firmly believed for many years afterwards that relief of mitral stenosis would not help the patient. One of the sceptics, Sir Thomas Lewis (the "father of clinical science") wrote in 1943: "Although many symptoms may be complained of by the patients suffering from mitral stenosis, there are none that can be ascribed properly and usefully to this deformity of the valve", ${ }^{3}$ an opinion proved wrong within a decade as closed valvotomy transformed the lives of thousands.

On the subject of aortic stenosis Lewis wrote: "There are no symptoms of aortic stenosis" and dismissed the subject with extreme brevity. 4 We now have a more mechanical and less philosophical view of the heart, at least as far as valve disease is concerned. Relief of aortic stenosis improves symptoms, lengthens expectation of life, ${ }^{5}$ and, even in those who do not complain of symptoms because the progress of their disability is insidious, valve replacement improves wellbeing and exercise tolerance. The point at issue is whether these benefits can also be obtained by balloon dilatation. ${ }^{6}$ To the surgeon at least, it seems inherently unlikely. Video pictures (screened in 1988 at the British Cardiac Society meeting) of balloon dilatation performed in vitro on excised valves did nothing to counter my prejudice against this procedure. $^{7}$

Brock led his contemporaries in attempts at closed aortic valvotomy and reported on 20 cases to the British Cardiac Society in $1954^{\circ}$ but the results were mechanically unsatisfactory. Relief of obstruction may result from commissurotomy of an otherwise flexible valve (as in mitral stenosis) but the type of aortic valve that we remove in elderly patients is usually a craggy, rigid, and completely hopeless looking structure. But to reject balloon dilatation because in theory we do not think that it should work is to treat enterprising cardiologists in the way Souttar was treated by his colleagues.

Protagonists of balloon dilatation report benefit not attended by the level of mortality that one might have feared. In recent series that included some severely compromised patients $^{9-13}$ there were eight early deaths in 130 patients $(70 \%$ confidence interval $4 \%-$ $9 \%$ ). This resembles the surgical (30 day) mortality which has varied between $4 \%$ and $6 \%$ between 1980 and 1985 . Stroke is rare, although vascular damage at the site of access was not uncommon. Getting the patient out of the catheter laboratory alive and without a stroke is creditable, but a more useful index of mortality is the proportion of patients that are alive at a year. In one series the mortality was $28 \%$ at six months and $55 \%$ at a year. ${ }^{12}$ Sprigings et al reported that less than half their patients were alive at a year. ${ }^{13}$

We also need to look carefully at the indices of success. The mean of the mean gradients falls by $31-41 \%$, but the truth might be hidden 
in all that averaging. First of all, the arithmetic mean is inappropriate for skewed data. In two papers where the raw data are available ${ }^{910}$ the preoperative mean gradients (86 and $84 \mathrm{~mm}$ $\mathrm{Hg}$ ) are influenced by high outliers, and the medians ( 70 and $75 \mathrm{~mm} \mathrm{Hg}$ ) may be more representative. More serious is the exaggeration of results by the enthusiastic use of $p$ values. Any test of difference, and the popular paired $t$ test has been used repeatedly both for gradient and valve area, will be highly "significant", however small the improvement, provided all changes are in the same direction, ${ }^{1415}$ which must be the case unless a substantial proportion of the valves become worse. Thus all the statements that the gradient is significantly reduced, or the valve area is significantly increased mean very little. The preoperative valve areas are estimated to be, on average, $0.5 \mathrm{~cm}^{2}$. The median valve area immediately after the procedure was $0.73 \mathrm{~cm}^{2}$ in 100 cases from five studies ${ }^{9-11} 1316$ so although the $\mathrm{p}$ value for difference may have been $<0.0001^{11}$ or even $<0.000001^{10}$ by the paired $t$ test, only 10 out of 100 cases had an aortic valve area of more than $1.0 \mathrm{~cm}^{2}$ after dilatation. Most still had severe aortic stenosis. The result for 442 patients in the French register was similar, with an increase in valve area from $0.48 \mathrm{~cm}^{2}$ to $0.80 \mathrm{~cm}^{2} .{ }^{17}$ Furthermore, these are early estimates of increased valve area which are not reproducible if the patient is restudied a week or more later. ${ }^{131618}$ Whether this is because of loss of actual benefit ${ }^{18}$ or because the early measurements are inaccurate because of reduced flow is a matter of conjecture.

So we are no longer discussing a means of relieving aortic stenosis but, at best, of creating a margin of benefit sufficient for some specific purpose. For example, if a patient with aortic stenosis needs other emergency surgery balloon dilatation may produce enough improvement to permit anaesthesia, and this seems to be a reasonable approach. ${ }^{1920}$ Also improvement in a patient with very low cardiac output may make valve replacement safer. ${ }^{21}$ Balloon dilatation does not seem to be justified in patients with terminal carcinoma ${ }^{9}$ whose life it might extend long enough for them to die of something worse. The risks of balloon dilatation are higher in the elderly ${ }^{21}$ and age is not in itself a barrier to definitive valve replacement if relief of stenosis is justified on other grounds. ${ }^{21-24}$ In one of the earlier series five out of eight patients subsequently had surgery ${ }^{25}$ so there is some leeway in judging suitability for operation.

In fairness, I must say that all the groups that I have quoted were very guarded in their remarks about balloon dilatation and indicated the relatively poor relief of stenosis and the short duration of benefit. ${ }^{131618}$ Only two of the 32 patients studied by Sprigings et al had lasting benefit. ${ }^{13}$ It seems that the indications are already limited and enthusiasm is on the wane.

1 Souttar HS. The surgical treatment of mitral stenosis. $\mathrm{Br}$ Med J 1925;ii:603-6.

2 Letac B, Gerber LI, Koning R. Insights on the mechanism of balloon valvulopolasty in aortic stenosis. Am J Cardiol 1988;62:1241-7.

3 Lewis T. Diseases of the heart. 3rd ed. London: MacMillan, 1943:130.

4 Lewis T. Diseases of the heart. 3rd ed. London: MacMillan, 1943:127.

5 Horskotte D, Loogen F. The natural history of aortic stenosis. Eur Heart $J$ 1989;9(suppl E):57-64.

6 Cribier A, Savin T, Saoudi N, Rocha P, Berland J, Letac B. Percutaneous transluminal valvuloplasty of acquired aortic stenosis in elderly patients: an alternative to valve replacement? Lancet 1986;i:63-7.

7 Rosenthal E, Montarello JK, Perakis A, et al. Balloon dilatation of the aortic valve: an in vitro assessment of the mechanism, magnitude, and duration of its effects. the mechanism, magnitude, and durt

8 Brock RC. Valvotomy for aortic stenosis. [Abstract]. $B r$ Heart $J$ 1954;16:471.

9 Dancy M, Dawkins K, Ward D. Balloon dilatation of the aortic valve: limited success and early restenosis. Br Heart J 1989;60:236-9.

10 Serruys PW, Luijten HE, Beatt KJ, et al. Percutaneous balloon valvuloplasty for calcific aortic stenosis. A treatment "sine cure"? Eur Heart J 1988;9:782-94.

11 Orme EC, Wray RB, Barry WH, Krueger SK, Mason JW. Comparison of three techniques for percutaneous balloon aortic valvuloplasty of aortic stenosis in adults. Am Heart $J$ 1989;117:11-7.

12 Sherman W, Hershman R, Lazzam C, Cohen M, Ambrose J, Gorlin R. Balloon valvuloplasty in adult aortic stenosis: determinants of clinical outcome. Ann Intern Med 1989; 110:421-5.

13 Sprigings DC, Jackson G, Chambers JB, et al. Balloon dilatation of the aortic valve for inoperable aortic stenosis. dilatation of the aortic valve for

14 Evans SJW, Mills P, Dawson J. The end of the p value? $\mathrm{Br}$ Heart $J$ 1988;60:177-80.

15 Gardner MJ, Altman DG. Statistics with confidence. London: BMJ, 1989

16 Grollier G, Commeau P, Sesboué B, Huret B, Potier JC, Foucault JP. Short-term clinical and haemodynamic assessment of balloon aortic valvuloplasty in 30 elderly patients. Discrepancy between immediate and eighth-day haemodynamic values. Eur Heart $J$ 1988;9(suppl E): 155-62.

17 Cribier A, Berland J, Koning R, Bellefleur JP, Mechmeche $R$, Letac B. Percutaneous transluminal aortic valvuloplasty: indications and results in adult aortic stenosis. Eur Heart $J 1989 ; 9$ (suppl E):149-54.

18 Sievert H, Krämer P, Kober G, Bussmann W-D, Kaltenbach $M$. Restenosis is a common feature of the angiographic follow-up after balloon valvoplasty of calcified aortic phic follow-up after balloon valvoplasty of

19 Levine MJ, Berman AD, Safian RD, Diver DJ, McKay RG. Palliation of valvular aortic stenosis by balloon valvuloPalliation of valvular aortic stenosis by balloon valvulo-
plasty as preoperative preparation for noncardiac surgery. plasty as preoperative preparatio

20 Roth RB, Palacios IF, Block PC. Percutaneous aortic Roth RB, Palacios IF, Block PC. Percutaneous aortic
balloon valvuloplasty: its role in the management of patients with aortic stenosis requiring major noncardiac surgery. J Am Coll Cardiol 1989;13:1039-41.

21 Brady ST, Davis CA, Kussmaul WG, Laskey WK, Hirshfield JW, Herrmann HC. Percutaneous aortic balloon valvuloplasty in octagenarians: morbidity and mortality. Ann Intern Med 1989;110:761-6.

22 Acar J, Vahanian A, Slama M, et al. Treatment of calcified aortic stenosis: surgery or percutaneous transluminal aortic valvuloplasty? Eur Heart J 1988;9(suppl E):163-8.

23 Markland CG, Pugsley WG, Treasure T, Swanton RH. Is there a limit to operability in aortic stenosis? [Abstract] $\mathrm{Br}$ Heart $J 1989 ; 61: 126$.

24 Millner R, Treasure T, Swanton H. Percutaneous balloon valve dilatation. BMJ 1989;298:1181-2.

25 Dancy M, Redwood D, Pumphrey CW, Ward DE. Balloon aortic valvuloplasty: high frequency of early recurrence of aortic valvuloplasty: high frequency of early recurre
aortic stenosis [Abstract]. Br Heart J 1987;57:561. 